\title{
Variation in Pea (Pisum sativum L.) Seed Quality Traits Defined by Physicochemical Functional Properties
}

\author{
Carla S. Santos ${ }^{1,+}\left(\mathbb{D}\right.$, Bruna Carbas $^{2,+}{ }^{,}$Ana Castanho ${ }^{2}$, Marta W. Vasconcelos ${ }^{1}{ }^{\mathbb{D}}$, \\ Maria Carlota Vaz Patto ${ }^{3}$ (D), Claire Domoney ${ }^{4}$ (D) and Carla Brites ${ }^{2, *(\mathbb{D})}$ \\ 1 Universidade Católica Portuguesa, CBQF-Centro de Biotecnologia e Química Fina-Laboratório Associado, \\ Escola Superior de Biotecnologia, Rua Diogo Botelho 1327, 4169-005 Porto, Portugal; \\ cssantos@porto.ucp.pt (C.S.S.); mvasconcelos@porto.ucp.pt (M.W.V.) \\ 2 INIAV-Instituto Nacional de Investigação Agrária e Veterinária, Avenida da República, 2780-157 Oeiras, \\ Portugal; bruna.carbas@iniav.pt (B.C.); anavargascastanho@gmail.com (A.C.) \\ 3 ITQB NOVA-Instituto de Tecnologia Química e Biológica António Xavier, Universidade Nova de Lisboa, \\ Avenida da República, 2780-157 Oeiras, Portugal; cpatto@itqb.unl.pt \\ 4 John Innes Centre, Norwich Research Park, Norwich NR4 7UH, UK; claire.domoney@jic.ac.uk \\ * Correspondence: carla.brites@iniav.pt; Tel.: +351-214403500 \\ + These authors contributed equally to this work.
}

Received: 20 September 2019; Accepted: 11 November 2019; Published: 13 November 2019

\begin{abstract}
Pea is one of the most produced and consumed pulse crops around the world. The study of genetic variability within pea germplasm is an important tool to identify outstanding accessions with optimal functional and nutritional qualities. In the present study, a collection of 105 pea accessions was analysed for physicochemical properties, pasting viscosity, and basic composition parameters. While pasting viscosities were negatively correlated to hydration capacity, cooking time, and basic composition, a positive correlation was found between the hydration capacity and the basic composition parameters. Basic composition (protein, fibre, fat, and resistant starch) parameters were further evaluated regarding seed trait morphology, namely, seed shape, colour, and surface. Allelic characterisation at the $r$ and $r b$ genetic loci was performed in a subgroup of 32 accessions ( 3 phenotyped as smooth and 29 as rough seeded), revealing that none of the initially classified rough-seeded accessions were $r b$ mutants, 19 were $r$ mutants, and 13 were neither $r$ nor $r b$. Despite their initial phenotypic classification, the 13 accessions genetically classified as smooth behaved differently $(p<0.05)$ to the $19 r$ mutants in terms of physicochemical properties, pasting viscosity, and basic composition parameters. Using multivariate analysis of the most discriminatory parameters for the food-related traits studied, the best-performing accessions at functional and nutritional levels were identified for future plant breeding to improve field pea production and consumption.
\end{abstract}

Keywords: cooking quality; genetic markers; pea flour; protein; pulses; rapid visco analyser profile; resistant starch; seed phenotype

\section{Introduction}

Field pea (Pisum sativum) is an increasingly important legume crop grown around the world, having a total harvested area of 8 million ha and a total production of 16 million tonnes per year [1]. Currently, Europe secures a pea production share of about $44 \%$, followed by America and Asia. Of the total 5.1 million tonnes of pulses produced in Europe, field pea accounts for more than $40 \%$ of the production volume [1,2]. To increase their consumption and avail consumers of their functional and nutritional advantages, legume (pulse) seeds are being processed into flours to be used as ingredients 
in the preparation of new food formulations [3-5]. The seeds of pulse crops have a valuable nutrition profile, with high protein content, minerals, carbohydrates, and fibre [6]. Amongst the carbohydrate fractions, the most abundant component is starch which, in the case of pulses, has a low glycemic index [7]. The low digestibility of starch from pulses is one of the main reasons why they can provide high nutritional value to humans, given that part of the starch fraction-resistant starch-is not digested by the small intestine and functions similarly to dietary fibres, accounting for its several health benefits [8]. Additionally, the lack of gluten proteins in pulse seeds is very important in helping to meet the demands of gluten-free diets for people who suffer from celiac disease [8].

One important characteristic that influences the acceptability of legume food products relates to food texture and sensory qualities, for which the pasting profile of starch has been shown to be important in different legume species [9]. However, limited studies have focused on variability in the pasting profiles of starch in seeds from large collections of pea germplasm. The pasting properties of food result from the transformation of starch granules through the application of heat in the presence of water. Since certain seed quality characteristics like the cooking behaviour or the proximate composition of different pea accessions can vary according to seed traits like size, shape, or colour [10,11], it is important to understand the relationships between these factors and such characteristics [12]. The profile of pea starch pasting varies significantly among pea cultivars $[12,13]$. Both genotype and environment were found to exert a significant impact on the flour pasting characteristics of nine field pea genotypes harvested from two different growing sites [14,15].

Throughout the continuous selection and breeding of pea, different varieties have been developed for different food and feed uses. Several classes of pea have been bred for food use, the major classes being the vining (seeds harvested as immature vegetable) and combining (harvested as mature dry seed) types. However, the assessment of genetic diversity is crucial for identifying the best accessions for specific end-use requirements [16].

The wrinkled-seeded phenotype in pea has been associated with natural or induced mutations impacting on the concentrations of starch and sucrose; analysis of allelic variation at the $r$ and $r b$ loci has been used for screening variation in natural germplasm variants [17]. The phenotype of starch grains is also affected by mutations in pea, and compound starch grains are a feature of the natural and induced mutations at the $r$ locus which lead to a wrinkled-seeded phenotype [17].

Understanding trait and molecular diversity within pea germplasm will support investigations of the factors which affect the nutritional and functional properties of seeds and is thus of utmost importance to broadening the genetic basis of cultivated peas [15]. The aim of this study was to characterise the variability which exists among pea accessions from a worldwide representative collection of the germplasm used by European breeders, with a focus on their basic composition, resistant starch, pasting, and cooking behaviour, and to correlate these properties with seed morphological (shape, surface, colour) traits. A subset of samples was selected according to seed surface traits and analysed for allelic variation at the $r$ and $r b$ loci. Overall, the goal is to enable marker-assisted selection for cooking- and eating-quality-associated traits in pea.

\section{Materials and Methods}

\subsection{Plant Material}

For this study, 105 pea (P. sativum, PS201-305) accessions were selected from the breeding collection at the IAS-CSIC (Córdoba, Spain) germplasm bank (Table S1). The accessions were multiplied in Córdoba during 2014 under the same field conditions and were irrigated and hand-weeded as needed. Harvest was performed by hand, and seeds were stored at $5{ }^{\circ} \mathrm{C}$ until analysis. 


\subsection{Physicochemical Characteristics and Cooking Time}

Water hydration capacity (\% HC) and percentages of unhydrated seeds (US) were determined by the AACC 56-35.01 method [18]. Pea sample cooking times (minutes) were estimated by the Mattson Cooker method, as described [9].

\subsection{Pasting Properties, Resistant Starch, and Basic Composition}

Pea seeds were milled (Cyclone Falling 3100 with $0.8 \mathrm{~mm}$ mesh; Perten, Hägersten, Sweden) to produce flour.

Pasting properties were determined using a Rapid Visco Analyser according to AACC method 76-21 [19]. Pasting analysis was conducted on duplicate flour samples ( $3 \mathrm{~g}$ in $25 \mathrm{~mL}$ water) held at $50{ }^{\circ} \mathrm{C}$ for $1 \mathrm{~min}$, heated at $12{ }^{\circ} \mathrm{C} / \mathrm{min}$ to $95{ }^{\circ} \mathrm{C}$, held at $95^{\circ} \mathrm{C}$ for $2.5 \mathrm{~min}$, cooled subsequently at $12{ }^{\circ} \mathrm{C} / \mathrm{min}$ to $50{ }^{\circ} \mathrm{C}$, and held at $50^{\circ} \mathrm{C}$ for $3 \mathrm{~min}$. Peak, trough, breakdown, final viscosity, and setback from trough were expressed in centipoise $(\mathrm{cP})$.

The resistant starch was analysed according to AACC method 32-40.01 [20] using an assay kit (Megazyme International, Bray, Ireland).

Contents of protein, fibre, and fat were assessed using a near-infrared (NIR) analyser (MPA; Bruker, Billerica, MA, USA), with ground flour calibrations for grain legumes provided by Bruker $\left(n>500 ; R^{2}>90\right)$. The NIR data were validated with $10 \%$ of the samples selected to cover the range and characterised by the reference methods: protein by the combustion method ISO 16634-2:2016 [21], calculated by multiplying the nitrogen concentration by a conversion factor of 6.25 ; fat extracted by using petroleum ether in a Soxhlet apparatus according to ISO 6492:1999 [22]; and fibre by the intermediate filtration method, ISO 6865:2000 [23].

\subsection{Seed Trait Classification}

Pea seeds were classified according to different morphological traits (Figure 1): shape (elliptical, cylindrical, rhomboid, or irregular), surface (rough or smooth), and colour (cream yellow, yellow green, light green, dark green, brown, orange brown, green, or army green).

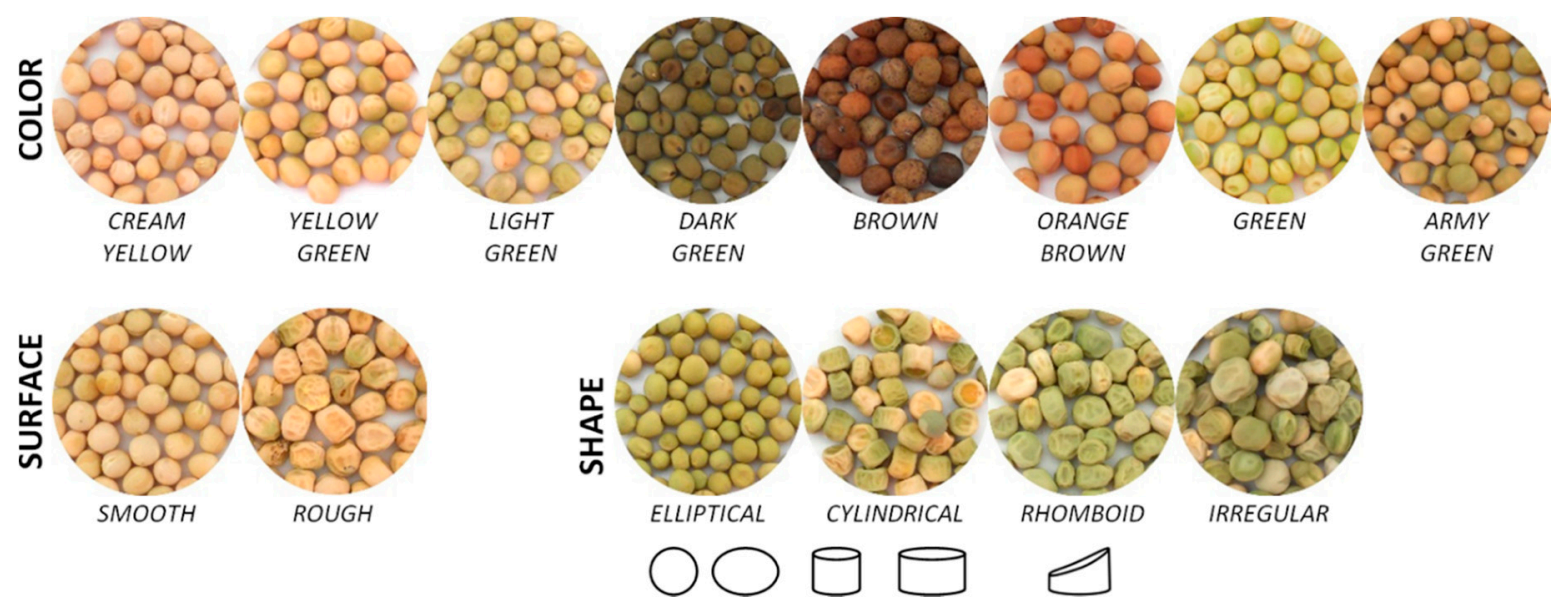

Figure 1. Pea seed categories defined for colour, surface, and shape. Geometric representations correspond to seed shape (elliptical, cylindrical and rhomboid).

A subset of lines (32) selected as having "rough" or "wrinkled" seeds (29 accessions) and three smooth (round-seeded) accessions $(259,286,289)$ with low viscosity profiles were genotyped at the $r$ and $r b$ genetic loci to determine the nature of the mutation which was impacting on the seed surface trait. The $r$ locus encodes starch-branching enzyme I, whereas the $r b$ locus encodes the large subunit of ADP-glucose pyrophosphrylase [17]. Seed meals were used for the extraction of DNA for 29 samples, and leaf DNA was extracted for the remaining three lines where high-quality DNA could not be 
extracted. A triplex assay was used to determine the nature of the $r$ locus, whereas the $r b$ allele was determined by sequencing, using PCR assays as previously described [17]. Starch granule shape appearance was determined by microscopy for this set of lines to validate the genotyping results. Four pea accessions of known genotype were included as controls in the DNA assays (JI 2822, RRrbrb, simple starch grains; JI 1194, rrRbRb, compound starch grains; JI 281, RRRbRb, simple starch grains; JI 399, RRrbrb, simple starch grains).

\subsection{Statistical Analysis}

Data were analysed using GraphPad Prism version 8.1.2 for Mac OS X (GraphPad Software, La Jolla California USA, www.graphpad.com). The variation within each seed trait was analysed by one-way analysis of variance (ANOVA). Physicochemical parameters determined for the genetically classified rough- and smooth-seeded accessions were compared by unpaired $t$-tests using the Holm-Šidák method. Statistical significance was considered at $p<0.05$.

Overall variation of the physicochemical, cooking, rheological, and basic composition characteristics was assessed by principal component analysis (PCA) using Tanagra data mining software, version 1.4.5 (Lyon, France) [24].

\section{Results and Discussion}

\subsection{Seed and Flour Variation in Pea Germplasm}

In the present work, a set of pea accessions (105) was analysed for variation in traits related to food end-use. In terms of 100-seed weight, the accessions 245, 246, 247, and 227 were the ones with lowest weight (below $10 \mathrm{~g}$ ), while the accessions 298, 221, 216, and 217 registered weights above $28 \mathrm{~g}$ (Figure 2a). Low seed weight has been shown to be related to the presence of relatively small-sized starch granules per unit area [25], which might impact hydration capacity and cooking time. The hydration capacity refers to the amount of water absorbed per $100 \mathrm{~g}$ of whole mature (dried) seeds. The accessions 246 and 247, which showed the lowest seed weights, also displayed relatively low hydration capacity (Figure 2b) and cooking time (Figure 2c). Despite the variability among the pea collection regarding cooking time (5-120 $\mathrm{min}$ ), the average of $33 \mathrm{~min}$ is low when compared to other pulses [9]. 
(a)

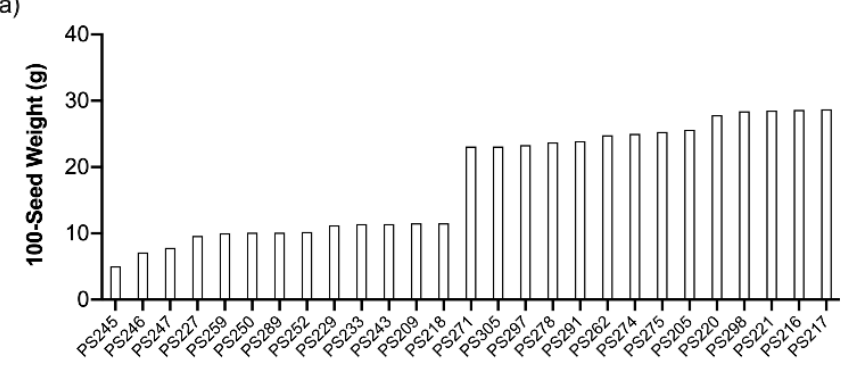

(b)

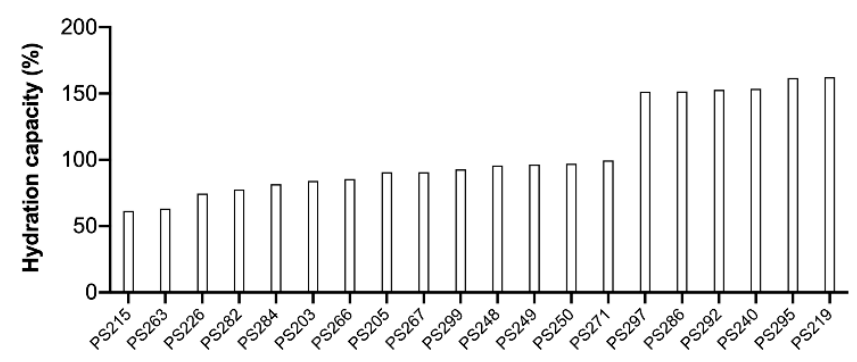

(c)

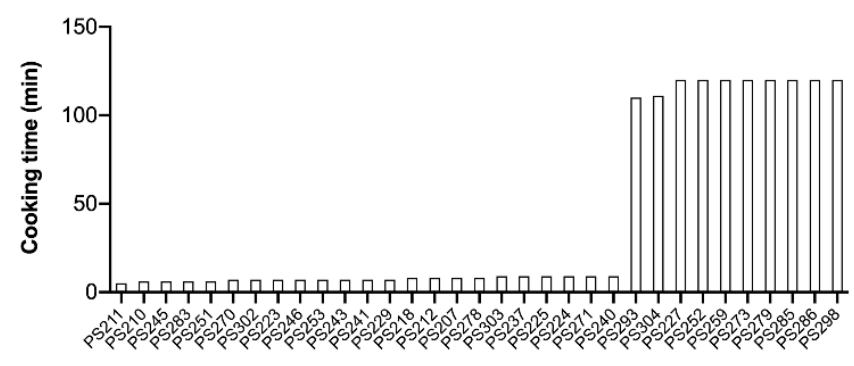

Pisum sativum accessions

Figure 2. Lowest- and highest-scoring pea (Pisum sativum) accessions for (a) 100-seed weight: 12 g-23 g; (b) hydration capacity: 100\%-150\%; and (c) cooking time: $10 \mathrm{~min}-100 \mathrm{~min}$.

In order to successfully substitute or partially replace wheat flour with pulse flour, it is important to understand how the resulting dough will perform in terms of its rheological properties. Pasting parameters, namely, peak, trough, breakdown, setback, and final viscosities, were analysed as these affect the processing conditions [15]. The analysis of the pasting viscosities (Table 1) showed that the peak viscosity, the maximum viscosity achieved by the samples, ranged between 83 and $4836 \mathrm{cP}$; the trough viscosity, which represents the decrease in paste viscosity caused by the disruption of starch granules, ranged between 58 and $4066 \mathrm{cP}$; the breakdown viscosity, the difference between the peak viscosity and trough viscosity, ranged between 8 and $867 \mathrm{cP}$; the final viscosity ranged from 212 to $7471 \mathrm{cP}$; and the setback viscosity, the difference between peak and final viscosity, was in the range 151-3489 cP. 
Table 1. Values for pasting, cooking, and proximate composition descriptors determined for 105 pea accessions (mean; relative standard deviation, RSD; range).

\begin{tabular}{lcc}
\hline \multicolumn{1}{c}{ Descriptor } & Mean \pm RSD & Range \\
\hline Physicochemical parameters & & \\
100-seed weight (g) & $18 \pm 28$ & $5-29$ \\
Hydration capacity (\%) & $116 \pm 17$ & $62-162$ \\
Unhydrated seeds (\%) & $10 \pm 88$ & $2-50$ \\
Cooking time (min) & $33 \pm 106$ & $5-120$ \\
\hline Pasting viscosities (cP $\left.{ }^{*}\right)$ & & \\
Peak & $2643 \pm 50$ & $83-4836$ \\
Trough & $2358 \pm 49$ & $58-4066$ \\
Breakdown & $285 \pm 67$ & $8-867$ \\
Final & $4018 \pm 50$ & $212-7471$ \\
Setback & $1660 \pm 54$ & $151-3489$ \\
\hline Basic composition (\%) & & \\
Protein & $22 \pm 0.1$ & $16-30$ \\
Fibre & $7 \pm 0.1$ & $6-10$ \\
Fat & $2 \pm 0.3$ & $1-3$ \\
Resistant Starch & $3 \pm 50$ & $1-7$ \\
\hline
\end{tabular}

${ }^{*} \mathrm{cP}$, centipoise.

The average values of the pasting properties of the 105 pea accessions were similar to those reported by others [14] and to the values obtained for other pulses, such as grass pea, chickpea, or lentil [9]. When compared to wheat varieties [26], the peak viscosity was generally lower, which could be related to differences in the amylose content of starches. In addition, the breakdown viscosity was lower for the pea collection described here $(285 \mathrm{cP})$ when compared to wheat values $(669 \mathrm{cP})$. This might present an advantage when incorporating pea flours into food formulations, since breakdown values are a measure of the degree of paste stability [26], and high breakdown viscosity can reduce the ability of flour to withstand heating during cooking [27]. The lower breakdown viscosities observed here are similar to those recently reported by others for pea and other pulses [28].

On average, the pea accessions contained $22 \%$ protein, $7 \%$ fibre, and $2 \%$ fat-values which are generally comparable to the values reported by others for this pulse $[6,12,15,29]$. The maximum resistant starch content was $7 \%$ in the pea accessions 220,221, and 228, which also showed higher peak and setback viscosities. Also, the average for the 105 accessions was $3 \%$, which is consistent with the observation that this pulse, when compared to others such as chickpea or lentil, has higher resistant starch percentages [6]. Once again, this is important since higher resistant starch contents lead to slower rates of digestion, enabling the use of pea starches in dietetic foods [30,31].

\subsection{Correlation Analysis of Pasting, Physicochemical, and Basic Composition Parameters}

Correlation coefficients estimated on the means of data from all pea accessions for pasting (trough viscosity, break viscosity, final viscosity, and setback viscosity), physicochemical parameters (100-seed weight, hydration capacity, unhydrated seeds, and cooking time) and basic composition (protein, fibre, fat, and resistant starch contents) are presented in Table 2. 
Table 2. Correlation coefficients of the traits ${ }^{\dagger}$ presented in Table 1 for the 105 pea accessions analysed.

\begin{tabular}{|c|c|c|c|c|c|c|c|c|c|c|c|c|}
\hline & Trough (cP) & Break (cP) & FV (cP) & $\mathrm{SB}(\mathrm{cP})$ & SW (g) & HC (\%) & US (\%) & $\mathrm{CT}$ (min) & Protein & Fibre & Fat & RS \\
\hline Peak & $1.000^{* *}$ & $0.804^{* *}$ & $0.989 * *$ & $0.949^{* *}$ & $0.218^{*}$ & $-0.631 * *$ & -0.005 & $-0.391 * *$ & $-0.443^{* *}$ & $-0.619 * *$ & $-0.759 * *$ & -0.269 * \\
\hline Trough & & $0.743 * *$ & $0.989^{* *}$ & $0.944^{* *}$ & $0.192 *$ & $-0.627^{* *}$ & -0.009 & $-0.397 * *$ & $-0.421^{* *}$ & $-0.613^{* *}$ & $-0.761^{* *}$ & -0.281 * \\
\hline Break & & & $0.764^{* *}$ & $0.768^{* *}$ & $0.333^{* *}$ & -0.518 ** & 0.015 & -0.264 * & $-0.475 * *$ & $-0.516^{* *}$ & $-0.572^{* *}$ & -0.136 \\
\hline FV & & & & 0.982 ** & 0.249 ** & -0.610 ** & -0.031 & $-0.373^{* *}$ & $-0.495^{* *}$ & $-0.610^{* *}$ & $-0.741^{* *}$ & -0.263 * \\
\hline SB & & & & & $0.317^{* *}$ & $-0.568^{* *}$ & -0.059 & $-0.329 * *$ & $-0.577 * *$ & $-0.587 * *$ & $-0.690^{* *}$ & -0.230 * \\
\hline SW & & & & & & -0.011 & $-0.214^{*}$ & -0.007 & $-0.408^{* *}$ & $-0.303^{* *}$ & -0.058 & -0.068 \\
\hline $\mathrm{HC}$ & & & & & & & $-0.578^{* *}$ & 0.035 & $0.327^{* *}$ & $0.393^{* *}$ & $0.493^{* *}$ & $0.359^{* *}$ \\
\hline US & & & & & & & & 0.138 & 0.139 & 0.118 & 0.013 & -0.055 \\
\hline $\mathrm{CT}$ & & & & & & & & & -0.130 & $0.362^{* *}$ & $0.258^{*}$ & 0.146 \\
\hline Protein & & & & & & & & & & 0.211 * & 0.113 & 0.040 \\
\hline Fibre & & & & & & & & & & & $0.666^{* *}$ & $0.217^{*}$ \\
\hline Fat & & & & & & & & & & & & 0.132 \\
\hline
\end{tabular}

significance, respectively. 
As previously reported [9], all viscosity parameters were positively correlated with each other $(p<0.01)$. These were all positively correlated to 100 -seed weight $(p<0.05)$ but showed a significant negative correlation to hydration capacity, as well as cooking time (Table 2). This negative correlation may be due to the fact that viscosity parameters are highly related to the firmness and cooking quality of pulses [32], which is in turn also influenced by the starch composition. Here, the peak, trough, final, and setback viscosities were negatively correlated to resistant starch content $(p<0.05)$.

Further correlations were found when looking at the basic composition. Firstly, all nutritional components were negatively correlated to the viscosity parameters (Table 2). Concordantly, in landraces of Phaseolus bean, fat content was shown to be negatively correlated to peak viscosity, but protein content displayed a positive correlation [33]. Additional positive correlations between protein, fibre, fat, resistant starch, and hydration capacity were found $(p<0.01)$, in agreement with the literature [32,34]. Fibre and fat were also positively correlated with cooking time, possibly indicating the major role of these constituents in pea processing.

\subsection{Seed Trait Variation}

The means of the peak, trough, break, final, and setback viscosity, 100-seed weight, hydration capacity, unhydrated seeds, and cooking time for each class of seed shape, surface, and colour are presented in Table 3.

Table 3. Mean peak $\left(\mathrm{cP}^{*}\right)$, trough $(\mathrm{cP})$, break $(\mathrm{cP})$, final $(\mathrm{FV}, \mathrm{cP})$, and setback viscosities $(\mathrm{cP})$, seed weight (SW, g), hydration capacity (HC, \%), unhydrated seeds (US, \%), and cooking time (CT, min) traits determined for 105 pea accessions within the classes distinguished by seed shape, colour, and surface $^{\dagger}$.

\begin{tabular}{|c|c|c|c|c|c|c|c|c|c|}
\hline & Peak & Trough & Break & FV & Setback & SW & $\mathrm{HC}$ & US & CT \\
\hline \multicolumn{10}{|l|}{ Shape } \\
\hline Ellipsoid $(n=42)$ & $3252^{a}$ & $2910^{a}$ & $342^{\mathrm{a}}$ & $4938^{a}$ & $2028^{a}$ & $17^{\mathrm{a}}$ & $109^{a}$ & $10^{\mathrm{a}}$ & $22^{a}$ \\
\hline Cylindrical $(n=24)$ & $3066^{a}$ & $2726^{a}$ & $340^{a}$ & $4632^{a}$ & $1906^{a b}$ & $19^{a}$ & $112^{a}$ & $11^{\mathrm{a}}$ & $27^{\mathrm{ab}}$ \\
\hline Rhomboid $(n=11)$ & $1953^{b}$ & $1716^{b}$ & $236^{a b}$ & $2944^{b}$ & $1228^{b}$ & $16^{a}$ & $121^{\mathrm{ab}}$ & $10^{\mathrm{a}}$ & $51^{b c}$ \\
\hline Irregular $(n=16)$ & $582^{c}$ & $496^{c}$ & $86^{b}$ & $918^{c}$ & $422^{c}$ & $18^{a}$ & $135^{b}$ & $13^{\mathrm{a}}$ & $67^{c}$ \\
\hline n.d. $(n=12)$ & $3046^{a}$ & $2759^{a}$ & $287^{a}$ & $4684^{a}$ & $1925^{a b}$ & $19^{a}$ & $115^{\mathrm{a}}$ & $9^{a}$ & $16^{\mathrm{ab}}$ \\
\hline \multicolumn{10}{|l|}{ Colour } \\
\hline Cream yellow $(n=9)$ & $3107^{a b}$ & $2765^{a b}$ & $342^{\mathrm{a}}$ & $4727^{a b}$ & $1962^{a b}$ & $19^{a}$ & $111^{a b}$ & $8^{a b}$ & $11^{\mathrm{a}}$ \\
\hline Yellow green $(n=24)$ & $3120^{a}$ & $2777^{a}$ & $342^{a}$ & $4736^{a}$ & $1958^{a}$ & $19^{a}$ & $112^{\mathrm{a}}$ & $9^{a}$ & $23^{a}$ \\
\hline Light green $(n=14)$ & $2200^{a b}$ & $1933^{a b}$ & $267^{a}$ & $3365^{a b}$ & $1432^{a b}$ & $19^{a}$ & $126^{a b}$ & $8^{a}$ & $34^{\mathrm{a}}$ \\
\hline Dark green $(n=8)$ & $2677^{a b}$ & $2420^{a b}$ & $257^{\mathrm{a}}$ & $3957 \mathrm{ab}$ & $1537^{a b}$ & $11^{b}$ & $103^{a}$ & $15^{\mathrm{ab}}$ & $51^{a}$ \\
\hline Green $(n=23)$ & $1744^{b}$ & $1548^{\mathrm{b}}$ & $196^{a}$ & $2609^{b}$ & $1061^{b}$ & $18^{a}$ & $128^{b}$ & $9^{a}$ & $44^{\mathrm{a}}$ \\
\hline Army green $(n=5)$ & $3172^{a b}$ & $2800^{a b}$ & $372^{a}$ & $4849^{a b}$ & $2049^{a b}$ & $16^{\mathrm{ab}}$ & $99^{\mathrm{a}}$ & $23^{b}$ & $52^{a}$ \\
\hline Brown $(n=8)$ & $2938^{a b}$ & $2608^{a b}$ & $331^{a}$ & $4491^{a b}$ & $1883^{a b}$ & $17^{a b}$ & $103^{a}$ & $16^{\mathrm{ab}}$ & $39^{a}$ \\
\hline Orange brown $(n=2)$ & $3210^{a b}$ & $3014^{a b}$ & $197^{\mathrm{a}}$ & $5255^{a b}$ & $2241^{\mathrm{ab}}$ & $21^{a b}$ & $113^{a}$ & $9^{a b}$ & $64^{a}$ \\
\hline n.d. $(n=12)$ & $3046^{a b}$ & $2759^{a b}$ & $287^{a}$ & $4684^{a b}$ & $1925^{a b}$ & $19^{a}$ & $115^{a b}$ & $9^{a b}$ & $16^{a}$ \\
\hline \multicolumn{10}{|l|}{ Surface } \\
\hline Rough $(n=29)$ & $1475^{a}$ & $1302^{a}$ & $172^{\mathrm{a}}$ & $2249^{a}$ & $947^{\mathrm{a}}$ & $19^{a}$ & $127^{\mathrm{a}}$ & $11^{\mathrm{a}}$ & $47^{\mathrm{a}}$ \\
\hline Smooth $(n=64)$ & $3097^{b}$ & $2761^{b}$ & $336^{b}$ & $4694^{b}$ & $1933^{b}$ & $17^{\mathrm{a}}$ & $110^{b}$ & $10^{\mathrm{a}}$ & $30^{a b}$ \\
\hline n.d. $(n=12)$ & $3046^{b}$ & $2759^{b}$ & $287^{a b}$ & $4684^{b}$ & $1925^{b}$ & $19^{a}$ & $115^{a b}$ & $9^{a}$ & $16^{\mathrm{b}}$ \\
\hline
\end{tabular}

${ }^{\dagger}$ within column and seed trait, means followed by the same letter are not significantly different at $p=0.05$; n.d., not determined; ${ }^{*} \mathrm{cP}$, centipoise.

Regarding seed shape, most accessions had ellipsoid $(n=42)$ and cylindrical $(n=24)$ shapes, and these were the types of seeds with higher viscosity values (Table 3). Irregular seeds displayed significantly longer cooking time when compared to ellipsoid or cylindrical seeds (Table 3). Irregular seeds showed higher protein and resistant starch contents when compared to ellipsoid and cylindrical seeds (Table 4). 
Table 4. Mean protein, fibre, fat, and resistant starch (RS) values (\%) determined for pea germplasm (105 accessions) within the classes distinguished by seed shape, colour, and surface ${ }^{\dagger}$.

\begin{tabular}{ccccc}
\hline & Protein (\%) & Fibre (\%) & Fat (\%) & RS (\%) \\
\hline Shape & & & & \\
Ellipsoid $(n=42)$ & $22 \pm 2.0^{\mathrm{a}}$ & $7 \pm 0.91^{\mathrm{a}}$ & $2 \pm 0.41^{\mathrm{a}}$ & $3 \pm 1.7^{\mathrm{a}}$ \\
Cylindrical $(n=24)$ & $22 \pm 1.6^{\mathrm{a}}$ & $7 \pm 0.75^{\mathrm{a}}$ & $2 \pm 0.28^{\mathrm{a}}$ & $3 \pm 1.5^{\mathrm{a}}$ \\
Rhomboid $(n=11)$ & $23 \pm 3.1^{\mathrm{ab}}$ & $8 \pm 0.95^{\mathrm{a}}$ & $2 \pm 0.57^{\mathrm{a}}$ & $4 \pm 1.7^{\mathrm{a}}$ \\
Irregular $(n=16)$ & $24 \pm 2.1^{\mathrm{b}}$ & $8 \pm 0.66^{\mathrm{a}}$ & $2 \pm 0.42^{\mathrm{a}}$ & $5 \pm 1.1^{\mathrm{b}}$ \\
n.d. $(n=12)$ & $23 \pm 3.4^{\mathrm{ab}}$ & $7 \pm 1.3^{\mathrm{a}}$ & $2 \pm 0.60^{\mathrm{a}}$ & $3 \pm 1.7^{\mathrm{a}}$ \\
\hline Colour & & & & \\
Cream yellow $(n=9)$ & $21 \pm 1.4^{\mathrm{ac}}$ & $6 \pm 0.67^{\mathrm{a}}$ & $2 \pm 0.30^{\mathrm{a}}$ & $3 \pm 0.82^{\mathrm{ab}}$ \\
Yellow green $(n=24)$ & $22 \pm 1.7^{\mathrm{ab}}$ & $7 \pm 0.77^{\mathrm{a}}$ & $2 \pm 0.41^{\mathrm{a}}$ & $3 \pm 1.8^{\mathrm{ab}}$ \\
Light green $(n=14)$ & $22 \pm 1.7^{\mathrm{abc}}$ & $8 \pm 0.89^{\mathrm{a}}$ & $2 \pm 0.61^{\mathrm{a}}$ & $5 \pm 1.5^{\mathrm{a}}$ \\
Dark green $(n=8)$ & $24 \pm 2.7^{\mathrm{b}}$ & $8 \pm 0.75^{\mathrm{a}}$ & $2 \pm 0.36^{\mathrm{a}}$ & $3 \pm 1.0^{\mathrm{ab}}$ \\
Green $(n=23)$ & $23 \pm 1.9^{\mathrm{bc}}$ & $8 \pm 1.1^{\mathrm{a}}$ & $2 \pm 0.53^{\mathrm{a}}$ & $4 \pm 1.8^{\mathrm{ab}}$ \\
Army green $(n=5)$ & $22 \pm 3.3^{\mathrm{ab}}$ & $7 \pm 0.71^{\mathrm{a}}$ & $2 \pm 0.29^{\mathrm{a}}$ & $3 \pm 2.2^{\mathrm{ab}}$ \\
Brown $(n=8)$ & $22 \pm 3.3^{\mathrm{ab}}$ & $7 \pm 0.93^{\mathrm{a}}$ & $2 \pm 0.35^{\mathrm{a}}$ & $3 \pm 1.5^{\mathrm{b}}$ \\
Orange-brown $(n=2)$ & $21 \pm 0.69^{\mathrm{ab}}$ & $7 \pm 0.67^{\mathrm{a}}$ & $2 \pm 12^{\mathrm{a}}$ & $2 \pm 0.40^{\mathrm{ab}}$ \\
n.d. $(n=12)$ & $23 \pm 3.4^{\mathrm{ab}}$ & $7 \pm 1.3^{\mathrm{a}}$ & $2 \pm 60^{\mathrm{a}}$ & $4 \pm 1.7^{\mathrm{ab}}$ \\
\hline Surface & & & & \\
Rough $(n=29)$ & $23 \pm 2.5^{\mathrm{a}}$ & $8 \pm 0.90^{\mathrm{a}}$ & $2 \pm 0.52^{\mathrm{a}}$ & $4 \pm 1.7^{\mathrm{a}}$ \\
Smooth $(n=64)$ & $22 \pm 1.8^{\mathrm{b}}$ & $7 \pm 0.93^{\mathrm{a}}$ & $2 \pm 0.42^{\mathrm{a}}$ & $3 \pm 1.6^{\mathrm{a}}$ \\
n.d. $(n=12)$ & $23 \pm 3.4^{\mathrm{a}}$ & $7 \pm 1.3^{\mathrm{a}}$ & $2 \pm 0.60^{\mathrm{a}}$ & $4 \pm 1.7^{\mathrm{a}}$ \\
\hline
\end{tabular}

${ }^{\dagger}$ within column and seed trait, means followed by the same letter are not significantly different at $p=0.05$; .d., not determined.

Regarding seed colour, the variability was not as high for all parameters as it was for seed shape (Table 3). However, most seeds showed a yellow green $(n=24)$ or green $(n=23)$ colour. Significant differences were found between these two groups for peak, trough, final, and setback viscosities, where yellow green seeds had higher values. They also differed in hydration capacity, where yellow green seeds had lower values (Table 3). Analysis of the basic composition variability (Table 4) showed that dark green seeds had higher protein content than cream yellow, and light green seeds had the highest resistant starch content, this difference being significant when compared to brown-coloured seeds.

Variation in seed surface type among the lines was apparent, and the majority of seeds were smooth $(n=64)$. These seeds had higher viscosity parameters $(p<0.05)$ and shorter cooking time $(p>0.05)$ (Table 3$)$. When looking at basic composition, the only significant difference detected between the two seed surface types was that smooth seeds have a lower protein content when compared to rough seeds (Table 4 ).

\subsection{Characterisation of Allelic Variation at the $r$ and $r b$ Genetic Loci}

For the 32 selected lines, genotyping analysis revealed that none of these were $r b$ mutants, 19 were $r$ mutants, and 13 were neither $r$ nor $r b$ (Table 5). The seed granule morphology scores confirmed the genotyping results, where the $r$ accessions showed a compound granule structure, and those lines which were neither $r$ nor $r b$ showed a simple starch granule structure (Table 5). The controls included three rough-seeded lines (JI 1194, JI 2822, and JI 399 as one $r$ mutant and two $r b$ mutant lines) and one wild-type smooth-seeded line (JI 281). 
Table 5. The $r$ and $r b$ genotypes of 32 pea accessions and their starch granule phenotypes, in comparison with four control pea lines of known genotype (JI 2822, JI 1194, JI 281, and JI 399).

\begin{tabular}{|c|c|c|c|c|c|}
\hline Accession Number & $r$ Allele & $r b$ Allele & Starch Granule & DNA Assayed & Surface \\
\hline 213 & $r$ & $R b$ & compound & seed meal & \\
\hline 222 & $R$ & $R b$ & simple & seed meal & \\
\hline 226 & $R$ & $R b$ & simple & leaf & \\
\hline 240 & $R$ & $R b$ & simple & seed meal & \\
\hline 241 & $R$ & $R b$ & simple & seed meal & \\
\hline 242 & $R$ & $R b$ & simple & seed meal & \\
\hline 244 & $R$ & $R b$ & simple & seed meal & \\
\hline 246 & $R$ & $R b$ & simple & seed meal & \\
\hline 247 & $R$ & $R b$ & simple & leaf & \\
\hline 256 & $r$ & $R b$ & compound & seed meal & \\
\hline 257 & $r$ & $R b$ & compound & seed meal & \\
\hline 258 & $r$ & $R b$ & compound & seed meal & \\
\hline 259 & $r$ & $R b$ & compound & seed meal & \\
\hline 261 & $r$ & $R b$ & compound & seed meal & \\
\hline 272 & $r$ & $R b$ & compound & seed meal & \\
\hline 273 & $r$ & $R b$ & compound & seed meal & \\
\hline 279 & $r$ & $R b$ & compound & seed meal & \\
\hline 282 & $R$ & $R b$ & simple & seed meal & \\
\hline 285 & $r$ & $R b$ & compound & seed meal & \\
\hline 286 & $r$ & $R b$ & compound & seed meal & \\
\hline 287 & $R$ & $R b$ & simple & seed meal & \\
\hline 288 & $r$ & $R b$ & compound & seed meal & \\
\hline 289 & $r$ & $R b$ & compound & seed meal & \\
\hline 291 & $R$ & $R b$ & simple & seed meal & \\
\hline 292 & $r$ & $R b$ & compound & seed meal & \\
\hline 293 & $r$ & $R b$ & compound & seed meal & \\
\hline 294 & $r$ & $R b$ & compound & seed meal & \\
\hline 295 & $r$ & $R b$ & compound & seed meal & \\
\hline 296 & $r$ & $R b$ & compound & seed meal & \\
\hline 297 & $r$ & $R b$ & compound & seed meal & \\
\hline 298 & $R$ & $R b$ & simple & seed meal & \\
\hline 299 & $R$ & $R b$ & simple & leaf & \\
\hline Control (JI 2822) & $R$ & $r b$ & simple & leaf & rough \\
\hline Control (JI 1194) & $r$ & $R b$ & compound & leaf & rough \\
\hline Control (JI 281) & $R$ & $R b$ & simple & leaf & smooth \\
\hline Control (JI 399) & $R$ & $r b$ & simple & leaf & rough \\
\hline
\end{tabular}

On the basis of these results, it seems likely that 13 of the 29 classified as having "rough-seeded" phenotypes were genetically round (smooth) seeded and that the three lines classified as having "smooth-seeded" phenotypes $(259,286,289)$ with low viscosity profiles were genetically "rough-seeded".

The 13 lines initially classified as "rough"-seeded which were scored as $R R R b R b$, genetically classified as "smooth", demonstrated the strong environmental effect on the seed surface trait phenotype which led to difficulties in obtaining consistent classification scores across different growth seasons or generations. It has been shown previously that two mutations $(r, r b)$ account for the round-/wrinkled-seeded phenotype in a pea germplasm resource [17]. Premature harvest of round-seeded genotypes or premature desiccation as a result of stress will lead to a wrinkled appearance of the seeds when residual water is lost from seeds more rapidly than would be the norm.

These 13 genetically smooth-seeded accessions revealed different behaviour in regards to all of the components analysed in the present study when compared to the 19 rough-seeded accessions (Figure 3). For example, when looking at the physicochemical parameters (Figure 3a), smooth seeds 
had significantly lower hydration capacity, higher unhydrated seed percentage, and shorter cooking time. Also, in the viscosity profiles (Figure 3b), the smooth-seeded accessions exhibited significantly higher values (with the exception of accession 247). Finally, significant differences were also found between these two groups in basic composition (Figure 3c). Smooth seeds had significantly lower levels of fibre, fat, and resistant starch (but not protein) when compared to the rough-seeded accessions. It is interesting to note that three seed samples $(226,247,299)$ posed a problem for DNA preparation, and leaf DNA was required to enable the genotyping assays (Table 5). This may reflect differences, either genetic or environmental, in the nature of starch in the seeds of these lines, which can interfere with the isolation and purification of other seed components.

(a)

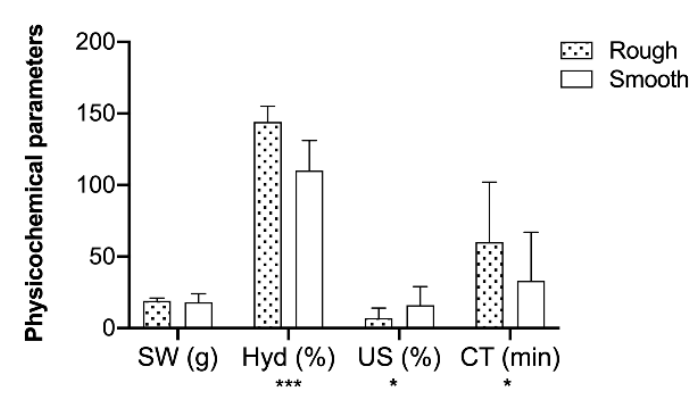

(b)

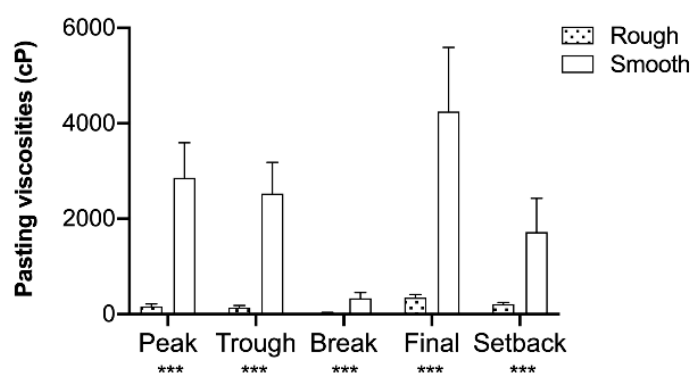

(c)

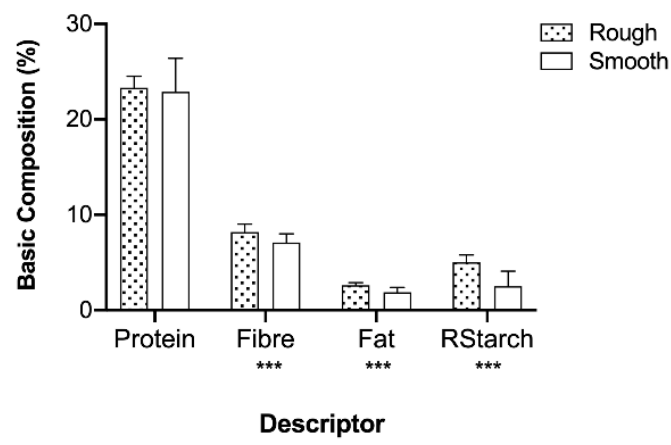

Figure 3. Physicochemical parameters determined for the genetically classified rough- $(n=19)$ and smooth-seeded ( $n=13)$ accessions; (a) seed weight, SW; hydration capacity, Hyd; unhydrated seeds, US; and cooking time, $\mathrm{CT}$; (b) pasting viscosities in centipoise, $\mathrm{CP}$; (c) basic composition: protein, fibre, fat, resistant starch (RStarch). Bars are means \pm SD. ${ }^{*}$ and ${ }^{* * *}$ indicate significant differences at $p<0.05$ and $p<0.001$, respectively, by unpaired $t$-tests using the Holm-Šidák method.

The molecular genetic basis for the different viscosity behaviours in the genetically rough-seeded accessions is the $r$ mutation and a consequence of the insertion in the starch-branching enzyme I-encoding gene (sbeI gene), affecting the carboxy-terminal region of the enzyme and the synthesis of amylopectin in developing pea seeds [35]. The mutation has been widely adopted by the vegetable industry and is the basis for most commercial vining cultivars. 


\subsection{Multivariate Analysis}

Principal component analysis was performed including the peak and setback viscosity values; morphological and cooking parameters, namely, 100-seed weight, hydration capacity, unhydrated seeds, and cooking time; and composition in terms of percentage of protein, fibre, fat, and resistant starch (Figure 4).

(a)

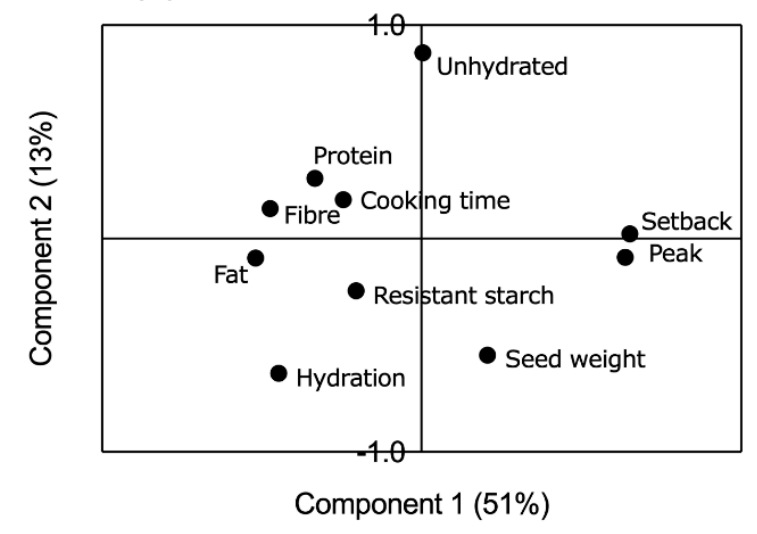

(b)

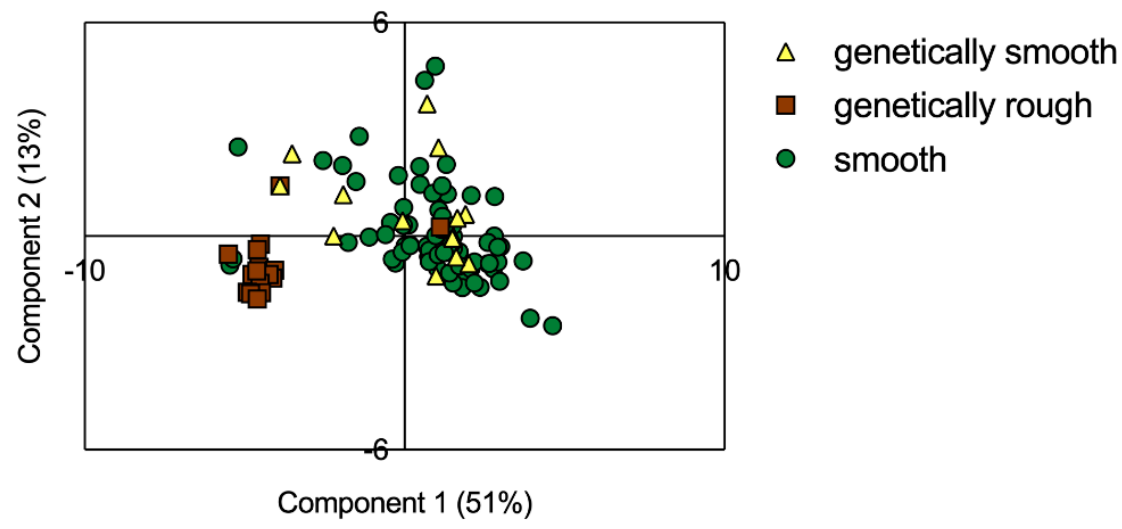

Figure 4. Principal component analysis of the factor loadings (a) and of sample scores by accession number (b) for the pea samples analysed; yellow triangles represent genetically classified smooth accessions, brown squares represent genetically classified rough accessions, and green circles represent smooth-phenotyped accessions.

The first two components justified 51\% (Component 1) and 13\% (Component 2) of the total variance, accounting for $64 \%$ of the variance. The first component had a positive correlation with basic composition parameters, cooking time, and hydration capacity, while viscosity parameters showed a negative correlation with these parameters (as also observed in Table 2). The second component showed a negative correlation with 100-seed weight and a positive one with the unhydrated seeds parameter (Figure 4a).

Along the first component, a group of 17 accessions was separated from the rest of the collection $(213,219,256,257,261,272,273,279,285,286,289,292,293,294,295,296,297)$, and these mostly corresponded to the group of genetically confirmed rough-seeded accessions. Hence, the seed surface trait seems to be highly correlated to fat, resistant starch, and hydration capacity.

Accessions 220, 221, and 300 showed higher peak and setback viscosity values; accessions 263, 215 , and 226 were separated from the group due to their higher percentage of unhydrated seeds; and accession 259 had higher percentages of fibre and fat (Figure $4 \mathrm{~b}$ ). 
Moreover, it is possible to confirm that the 13 accessions phenotyped as rough but genetically classified as smooth behave similarly to all 64 accessions initially phenotyped as smooth, and that the 19 accessions confirmed as "rough" constitute a separate group along the first component.

\section{Conclusions}

The present results highlight the value of molecular analyses combined with the study of quality parameters, enabling the selection of appropriate pea germplasm and breeding for discrete end uses.

The pea collection analysed here displayed a favourable pasting profile for the development of flour for baking and other food formulations. Results for protein, fibre, and fat contents were comparable to those from other pulses. Resistant starch values varied greatly, however, among the pea accessions analysed; this component was negatively correlated to the pasting viscosity, an important contributor to cooking property variation.

Phenotype-based characterisation distinguished seeds according to shape, colour, and surface traits. While for the shape and colour classes defined, the results of physicochemical analyses were scattered, in contrast, all parameters differed significantly between the rough- and smooth-seeded classes. Of these, 29 rough- and 3 smooth-seeded accessions were further characterised for their allelic variation at the $r$ and $r b$ genetic loci. Indeed, 13 of the rough-seeded phenotyped accessions were genetically characterised as smooth, and their physicochemical responses were similar to the behaviour of the other smooth-seeded accessions.

A final PCA study was performed wherein the pea accessions were separated according to their surface type, linking this trait to cooking and to nutritional value traits, mainly determined by fibre, fat, and resistant starch composition.

Supplementary Materials: The following are available online at http://www.mdpi.com/2304-8158/8/11/570/s1, Table S1: List of 105 pea accessions evaluated in 2014 in Cordoba, Spain, with the corresponding bank code number and origin.

Author Contributions: Conceptualisation, M.C.V.P., C.D., C.B.; Data curation, C.S.S.; Formal analysis, C.S.S.; Funding acquisition, M.W.V., M.C.V.P., C.B.; Methodology, B.C., A.C., C.D., C.B.; Project administration, M.W.V., C.B.; Resources, M.W.V., C.D., C.B.; Supervision, C.D., C.B.; Writing-original draft, C.S.S., C.B.; Writing-review and editing, C.S.S., B.C., M.W.V., M.C.V.P., C.D., C.B.

Funding: This research was funded by the European Union's Seventh Framework Programme for research, technological development and demonstration under grant agreement no. FP7-613551, LEGATO project; by Biotechnology and Biological Sciences Research Council (BBSRC) (BB/J004561/1, BB/P012523/1, BBS/E/J/000PR9799) and the John Innes Foundation, The Department for Environment, Food and Rural Affairs (Defra) (CH0103, CH0111, Pulse Crop Genetic Improvement Network), a BBSRC/Defra LINK project (BBSRC: BB/H009787/1; Defra: LK09126; AHDB: FV 351); and by Portuguese National Funds from Fundação para a Ciência e Tecnologia (FCT) through IF/01337/2014 FCT Investigator contract (MCVP) and research unit GREEN-IT (UID/Multi/04551/2019). The APC was funded by the FCT project PTDC/AGRPRO/3972/2014. The authors would also like to thank the scientific collaboration under the FCT project UID/Multi/50016/2019 and the European Union's Horizon 2020 research and innovation programme under grant agreement no. 727973, TRUE project.

Acknowledgments: The authors are grateful to Diego Rubiales's team (IAS-CSIC, Córdoba, Spain) for providing and multiplying seeds from the different pea accessions analysed; to Carol Moreau and Nikolai Kovzel, JIC, for carrying out the genotyping assays; and to Carmen Santos (ITQB NOVA) for leaf DNA extractions.

Conflicts of Interest: The authors declare no conflict of interest.

\section{References}

1. FAOSTAT. Peas, Dry, World's Area Harvested and Production Quantity. Available online: http://www.fao. org/faostat/en/?\#data/QC (accessed on 4 November 2019).

2. Eurostat. Eurostat Statistics Explained. Dry Pulses in EU Agriculture-Statistics on Cultivation, Production and Economic Value. Available online: https://ec.europa.eu/eurostat/statistics-explained/index.php?title= Dry_pulses_in_EU_agriculture___statistics_on_cultivation,_production_and_economic_value\#Structure_ of_production (accessed on 10 April 2019).

3. Foschia, M.; Horstmann, S.W.; Arendt, E.K.; Zannini, E. Legumes as functional ingredients in gluten-free bakery and pasta products. Annu. Rev. Food Sci. Technol. 2017, 8, 75-96. [CrossRef] 
4. Rempel, C.; Geng, X.; Zhang, Y. Industrial scale preparation of pea fractions with enhanced nutritive composition by dry fractionation. Food Chem. 2019, 276, 119-128. [CrossRef]

5. Cunha, L.M.; Fonseca, S.C.; Lima, R.C.; Loureiro, J.; Pinto, A.S.; Vaz Patto, M.C.; Brites, C. Consumer-driven improvement of maize bread formulations with legume fortification. Foods 2019, 8, 235. [CrossRef]

6. Tosh, S.M.; Farnworth, E.R.; Brummer, Y.; Duncan, A.M.; Wright, A.J.; Boye, J.I.; Marcotte, M.; Benali, M. Nutritional profile and carbohydrate characterization of spray-dried lentil, pea and chickpea ingredients. Foods 2013, 2, 338-349. [CrossRef]

7. Vaz Patto, M.C.; Amarowicz, R.; Aryee, A.N.A.; Boye, J.I.; Chung, H.J.; Martín-Cabrejas, M.A.; Domoney, C. Achievements and challenges in improving the nutritional quality of food legumes. Crit. Rev. Plant Sci. 2015, 34, 105-143. [CrossRef]

8. Singh, B.; Singh, J.P.; Shevkani, K.; Singh, N.; Kaur, A. Bioactive constituents in pulses and their health benefits. J. Food Sci. Technol. 2017, 54, 858-870. [CrossRef]

9. Santos, C.S.; Carbas, B.; Castanho, A.; Bronze, M.R.; Serrano, C.; Vasconcelos, M.W.; Vaz Patto, M.C.; Brites, C. Relationship between seed traits and pasting and cooking behaviour in a pulse germplasm collection. Crop Pasture Sci. 2018, 69, 892-903. [CrossRef]

10. Tripathi, S.; Sridhar, V.; Jukanti, A.K.; Suresh, K.; Rao, B.V.; Gowda, C.L.L.; Gaur, P.M. Genetic variability and interrelationships of phenological, physicochemical and cooking quality traits in chickpea. Plant Genet. Resour. Charact. Util. 2012, 10, 194-201. [CrossRef]

11. Serrano, C.; Carbas, B.; Castanho, A.; Soares, A.; Vaz Patto, M.C.; Brites, C. Characterisation of nutritional quality traits of a chickpea (Cicer arietinum) germplasm collection exploited in chickpea breeding in Europe. Crop Pasture Sci. 2017, 68, 1031-1040. [CrossRef]

12. Wang, S.; Sharp, P.; Copeland, L. Structural and functional properties of starches from field peas. Food Chem. 2011, 126, 1546-1552. [CrossRef]

13. Simsek, S.; Tulbek, M.C.; Yao, Y.; Schatz, B. Starch characteristics of dry peas (Pisum sativum L.) grown in the USA. Food Chem. 2009, 115, 832-838. [CrossRef]

14. Liu, C.; Wang, S.; Copeland, L.; Wang, S. Physicochemical properties and in vitro digestibility of starches from field peas grown in China. LWT Food Sci. Technol. 2015, 64, 829-836. [CrossRef]

15. Maharjan, P.; Penny, J.; Partington, D.L.; Panozzo, J.F. Genotype and environment effects on the chemical composition and rheological properties of field peas. J. Sci. Food Agric. 2019. [CrossRef] [PubMed]

16. Jain, S.; Kumar, A.; Mamidi, S.; McPhee, K. Genetic diversity and population structure among pea (Pisum sativum L.) cultivars as revealed by simple sequence repeat and novel genic markers. Mol. Biotechnol. 2014, 56, 925-938. [CrossRef] [PubMed]

17. Rayner, T.; Moreau, C.; Ambrose, M.; Isaac, P.G.; Ellis, N.; Domoney, C. Genetic variation controlling wrinkled seed phenotypes in Pisum: How lucky was Mendel? Int. J. Mol. Sci. 2017, 18, 1205. [CrossRef] [PubMed]

18. AACC International. AACC Approved Methods of Analysis: Method 56-35.01-Method for Determining Water Hydration Capacity and Percentage of Unhydrated Seeds of Pulses, 11th ed.; Cereals \& Grains Association: St. Paul, MN, USA, October 2007.

19. AACC International. AACC Approved Methods of Analysis: Method 76-21.02_General Pasting Method for Wheat or Rye Flour or Starch Using the Rapid Visco Analyser, 11th ed.; Cereals \& Grains Association: St. Paul, MN, USA, November 1999.

20. AACC International. AACC Approved Methods of Analysis: Method 32-40.01-Resistant Starch in Starch Samples and Plant Materials, 11th ed.; Cereals \& Grains Association: St. Paul, MN, USA, October 2002.

21. International Organization for Standardizatio (ISO). ISO 16634. Food Products-Determination of the Total Nitrogen Content by Combustion According to Dumas Principle and Calculation of the Crude Protein Content; International Organization for Standardization: London, UK, 2016.

22. International Organization for Standardizatio (ISO). ISO 6492. Animal Feeding Stuffs—Determination of Fat Content; International Organization for Standardization: London, UK, 1999.

23. International Organization for Standardizatio (ISO). ISO 6865. Animal Feeding Stuffs-Determination of Crude Fibre Content. Method with Intermediate Filtration; International Organization for Standardization: London, UK, 2000.

24. Rakotomalala, R. TANAGRA: Un Logiciel Gratuit Pour L'enseignement et la Recherche; Actes de EGC '2005RNTI-E-3; EGC: Lyon, France, 2005; Volume 2, pp. 697-702. 
25. Sharma, S.; Singh, N.; Virdi, A.S.; Rana, J.C. Quality traits analysis and protein profiling of field pea (Pisum sativum) germplasm from Himalayan region. Food Chem. 2015, 172, 528-536. [CrossRef] [PubMed]

26. Kumar, R.; Khatkar, B.S. Thermal, pasting and morphological properties of starch granules of wheat (Triticum aestivum L.) varieties. J. Food Sci. Technol. 2017, 54, 2403-2410. [CrossRef]

27. Adebowale, A.R.A.; Sanni, S.A.; Oladapo, F.O. Chemical, functional and sensory properties of instant yam-breadfruit flour. Niger. Food J. 2008, 26, 2-12. [CrossRef]

28. Li, L.; Yuan, T.Z.; Setia, R.; Raja, R.B.; Zhang, B. Characteristics of pea, lentil and faba bean starches isolated from air-classified flours in comparison with commercial starches. Food Chem. 2019, 276, 599-607. [CrossRef]

29. Nikolopoulou, D.; Grigorakis, K.; Stasini, M.; Alexis, M.N.; Iliadis, K. Differences in chemical composition of field pea (Pisum sativum) cultivars: Effects of cultivation area and year. Food Chem. 2007, 103, 847-852. [CrossRef]

30. Ratnayake, W.S.; Hoover, R.; Warkentin, T. Pea starch: Composition, structure and properties-A Review. Starch 2002, 54, 217-234. [CrossRef]

31. Bragazzi, N.L.; Martini, M.; Saporita, T.C.; Nucci, D.; Gianfredi, V.; Maddalo, F.; Capua, A.D.; Tovani, F.; Marensi, L. Chapter 17-Nutraceutical and functional food regulations in the European Union. In Developing New Functional Food and Nutraceutical Products; Bagchi, D., Nair, S., Eds.; Academic Press: Cambridge, MA, USA, 2017; pp. 309-322.

32. Abdel-Aal, E.M.; Ragaee, S.; Rabalski, I.; Warkentin, T.; Vandenberg, A. Nutrient content and ciscosity of Saskatchewan-grown pulses in relation to their cooking quality. Can. J. Plant Sci. 2019, 99, 67-77. [CrossRef]

33. Carbas, B.; Pathania, S.; Castanho, A.; Lourenço, D.; Veiga, I.M.; Vaz Patto, M.C.; Brites, C. Elucidating potential utilization of Portuguese commnon bean varieties in rice based processed foods. J. Food Sci. Technol. 2018, 55, 1056-1064. [CrossRef] [PubMed]

34. Ross, K.; Zhang, L.; Arntfield, S. Understanding water uptake from the induced changes occurred during processing: Chemistry of pinto and navy bean seed coats. Int. J. Food Prop. 2010, 13, 631-647. [CrossRef]

35. Bhattacharyya, M.K.; Smith, A.M.; Ellis, T.H.N.; Hedley, C.; Martin, C. The wrinkled-seed character of pea described by Mendel is caused by a transposon-like insertion in a gene encoding starch-branching enzyme. Cell 1990, 60, 115-122. [CrossRef] 